\title{
Reforma do Estado e evolução dos modelos de gestão pública no Brasil: a democracia deliberativa como fundamento de uma nova administração pública constitucional
}

Pedro Thomé de Arruda Neto*

\section{Modelos patrimonialista e burocrático como antecedentes históricos e primórdios da gestão pública e comodelo da administração pública contemporânea brasileira}

No modelo de gestão pública contemporânea brasileira convivem traços identificadores dos quatro momentos histórico-didáticos identificados pelos estudiosos da administração pública, a saber: patrimonialista, burocrático, gerencial e pós-gerencial. Este último, também conhecido como societal ou alternativo, ainda se encontra em construção teórico-pragmática e tem no instituto da democracia participativa constitucional seu elemento essencial.

Afastada a uniformidade de modelagem e o purismo teórico, é possível se identificar a preponderância de elementos do modelo burocrático de gestão na administração pública pátria (Bresser-Pereira, 2003), fato que não afasta a convivência paralela, dentro do sistema, de manifestações sociojurídico-políticas das outras três modelagens, mesmo que rarefeitas.

\footnotetext{
* Promotor de Justiça no Ministério Público do Distrito Federal e Territórios (MPDFT). Pesquisador do Centro de Estudos em Gestão e Políticas Públicas Contemporâneas da Universidade de São Paulo (GPublic-USP). Bacharel em administração pública pela Universidade de Brasília (UnB) e autor de artigos científico-jurídicos publicados em periódicos nacionais e internacionais.
} 
Padece esse modelo multifacetado de gestão adotado na administração pública brasileira de ineficácia social, quer pela ausência, quer pela inadequada prestação de serviços públicos básicos à população. Em um quadro, a realização do bem comum, da justiça social ${ }^{1}$ e a inclusão cidadã se tornam objetivos cada vez mais distantes de ser atingidos. Nessa mesma linha, o estímulo ao abuso do poder econômico e político, ocasionado pelo vácuo instalado ou pela ineficiência estatal, gera a institucionalização da violência, discriminação, marginalização, alienação e vulneração de parcelas relevantes da população (grupos sociais).

A burocracia, em uma abordagem de sua tipologia ideal, se assenta em uma distribuição horizontal e vertical das funções administrativas do Estado, segundo organogramas e esquemas previamente definidos de competências e tem na coordenação e no controle as funções primordiais para a garantia do seu adequado funcionamento.

Ocorre que a distribuição universal de todas as funções do Estado gera a primeira das grandes críticas à burocracia: o risco das tarefas públicas não programadas serem negligenciadas. Aliado a isso, a inerente falta de flexibilidade da burocracia diante das necessidades sociais voláteis e cambiantes gera a obsolescência da sua estrutura que para ser eficiente depende de coordenação e controle efetivos, nem sempre possíveis de serem concretizados, fato que gera seu "aspecto retrógrado", além de frustrar as justas expectativas do corpo social. ${ }^{2}$

Mesmo aqueles que enxergam a burocracia como tipo ideal para o adequado funcionamento estatal, como é o caso de Reinhold Zippelius, não poupam críticas ao modelo. Para o professor de teoria geral do Estado e filosofia do direito da Universidade Erlangen-Nürnberg (Zippelius, 1997) existiria uma diferença crucial entre estrutura burocrática e estilo burocrático de administração. Enquanto a estrutura burocrática aponta para uma racionalização do aparato estatal como um todo, a ambivalência do estilo burocrático peca pela fragmentação excessiva que dispersa o sentido de responsabilidade global do Estado e propicia a morosidade

\footnotetext{
${ }^{1}$ Para Paulo Nader (2009:112-113), a finalidade da justiça social consiste na proteção aos mais pobres e aos desamparados, mediante a adoção de critérios que favoreçam uma repartição mais equilibrada das riquezas e prestações adequadas de serviços públicos. Por sua vez, por bem comum entende-se um acervo de bens, criado pelo esforço e a participação ativa dos membros de uma coletividade e cuja missão é ajudar os indivíduos que dele necessitam para a realização de seus fins existenciais.

${ }^{2}$ As críticas à burocracia estendem-se ao campo da teoria organizacional, ligada à administração de empresas. Ela é alvo de críticas ainda mais contundentes. Um dos principais estudos sobre a burocracia foi apresentado por Merton (apud Chiavenato, 2003:271) que a qualifica como disfuncional, englobando aqui a ideia de tudo que ela produz como resultados, de forma imprevista. Voltada para si, baseada no formalismo excessivo, na hierarquização e ineficiência, revela-se sombra pálida do arquétipo idealizado e sistematizado pelo pensador alemão Max Weber, que, na segunda metade do século XIX, sob a égide do Estado liberal, lançou as bases da teoria da burocracia (Motta e Vasconcelos, 2008). Por oportuno, registre-se que a literatura é unânime em identificar a burocracia como modelo preponderantemente adotado pelo setor público mundo afora, não sendo uma peculiaridade do sistema pátrio.
} 
e os automatismos perigosos, além de retirar a suposta neutralidade no desempenho das funções estatais pelo servidor burocrático. Nesse sentido, Zippelius (1997:487-492) afirma:

Foi precisamente a proliferação cancerosa das burocracias, associada a um excesso de regulações, previdência e intervenções estatais, que fez com que entrasse na consciência colectiva que a assistência e tutela excessivas pelo Estado, mesmo quando se realizam em moldes do Estado de Direito, restringem a liberdade (\$§31, I, 35, IV). O seu crescente peso no jogo das forças estatais conduziu também inevitavelmente a uma politização das burocracias de um modo tal que contradiz a sua função neutral. Tudo isto levou a que um dos imperativos políticos mais prementes dos nossos tempos consista em desbastar as burocracias e limitar novamente a sua acção a uma medida razoável.

Como decorrência da expansão da democracia, do domínio capitalista, da maior diferenciação entre mercado, sociedade e Estado, estruturou-se no país o modelo burocrático com o escopo de superar o modelo patrimonialista de administração pública, vigente no Brasil nos períodos colonial, imperial e boa parte do período republicano - do séc. XVI até início do século XX.

Inúmeros são os estudos críticos da burocracia, mas há alguns textos clássicos como aqueles de Maurício Tragtenberg, em especial, o seu Burocracia e ideologia, de 1973, que merece registro por, entre outras coisas, trazer à tona a fragilidade da neutralidade axiológica levada a efeito por Max Weber nos seus estudos acerca da burocracia, especialmente por exacerbar a "neutralidade do sujeito observador" no processo e término da pesquisa, como sendo aquele que tem seu processo de ação guiado apenas pela razão, sem considerações acerca das imbricações ideológicas para o próprio indivíduo. Por isso, Tragtenberg (1992:205) registra:

A neutralidade axiológica defendida por Weber - embora reconheça a valoração no início do processo de pesquisa - e patente no universo niilista, refere-se a valores de conteúdo, onde o individualismo emerge interligado a valores formais, liberdade, igualdade, tolerância e justiça. Sendo moralmente neutro, permite que os valores sejam transformados em valores inteiramente opostos à ditadura, à intolerância, à discriminação racial ou social. [...] Representa, contudo, um momento "historicamente definido do processo da industrialização extensiva e mecanizada que realiza o aproveitamento capitalista da aplicação da ciência como resultado, na forma de tecnologia autonomizada no plano das representações ideológicas". 
Por sua vez, enxerga-se na adoção do modelo burocrático um avanço significativo no sentido de superação do modelo patrimonialista brasileiro, que foi historicamente facilitado pelo coronelismo e pela consequente fraudulência do processo eleitoral em uma república de poucos privilegiados e inúmeros perseguidos (Rocha, 1997), o que acabou por tornar a organização governamental mais um patrimônio a ser explorado do que uma estrutura funcional a serviço do interesse público.

O patrimonialismo brasileiro tem seus antecedentes históricos mais remotos em Portugal medieval, fato que, particularmente, facilitou o processo de unificação dessa nação, bem como propiciou o expansionismo ultramarino. Divergia a "nação lusitana" de seus contemporâneos europeus, que possuíam características administrativas ditadas pelo modelo feudal, descentralizado por excelência. Nesse sentido, confira-se a lição de Faoro (2001):

Estado patrimonial, portanto, e não feudal, o de Portugal medievo. Estado patrimonial já com direção pré-traçada, afeiçoado pelo direito romano, bebido na tradição e nas fontes eclesiásticas, renovado com os juristas filhos da Escola de Bolonha. A velha lição de Maquiavel, que reconhece dois tipos de principado, o feudal e o patrimonial, visto, o último, nas suas relações com o quadro administrativo, não perdeu o relevo e a significação. Na monarquia patrimonial, o rei se eleva sobre todos os súditos, senhor da riqueza patrimonial, dono do comércio - o reino tem um dominus, um titular da riqueza eminente e perpétua, capaz de gerir as maiores propriedades do país, dirigir o comércio, conduzir a economia como se fosse empresa sua. O sistema patrimonial, ao contrário dos direitos, privilégios e obrigações fixamente determinados do feudalismo, prende os servidores numa rede patriarcal, na qual eles representam a extensão da casa do soberano. [...]

Guerra, quadro administrativo, comércio, a supremacia do príncipe - quatro elementos da moldura do mundo social e político de Portugal. Dentro do quadro há um drama que precipitará a emergência de uma estrutura permanente, viva no Brasil, fixada na queda de uma dinastia, consolidada numa batalha, amadurecida com a expedição de Ceuta (1415).

O patrimonialismo se fundamenta na falta de distinção entre res publica ("coisa pública") e res principis ("coisa do príncipe"), figurando o Estado como mero apêndice do "poder do soberano". Os cargos públicos nesse modelo são preenchidos de forma aleatória ou arbitrária, sem a observância de regras claras. Sobre o tema, Max Weber (2004:253), em obra de referência, Economia e sociedade, assevera: 
A estereotipagem e apropriação monopolizadora dos poderes oficiais pelos detentores, como companheiros jurídicos, cria o tipo "estamental" do patrimonialismo. [...] Ao cargo patrimonial falta sobretudo a distinção burocrática entre a esfera "privada" e a "oficial". Pois também a administração política é tratada como assunto meramente pessoal do senhor, e a propriedade e o exercício de seu poder político, como parte integrante de seu patrimônio pessoal, aproveitável em forma de tributos e emolumentos. A forma em que ele exerce o poder é, portanto, objeto de seu livre-arbítrio, desde que a santidade da tradição, que interfere por toda parte, não lhe imponha limites mais ou menos firmes ou elásticos.

No Brasil, a própria ideia de "cordialidade", contida em Raízes do Brasil, obra de um dos maiores estudiosos do pensamento político brasileiro, Sérgio Buarque de Holanda (2008), está intimamente ligada ao modelo de gestão patrimonialista típico dos momentos inaugurais da história do país e objeto de enfrentamento acadêmico pelo modelo burocrático-weberiano. Para Holanda, o homem cordial é avesso à impessoalidade, fato que constitui entrave histórico à transparência e manutenção da equidistância nas relações com o Estado. Nesse panorama, segundo Weffort (2006:283):

Um dos aspectos interessantes de Raízes do Brasil é a ideia da "cordialidade", ou do homem cordial, expressão com a qual o autor pretendia, à maneira de Max Weber, caracterizar a típica afetividade da cultura e da sociedade brasileiras. A cordialidade tradicional - que diria respeito ao coração, à emoção, ao afeto - tornaria difícil conceber a moderna impessoalidade das relações sociais, em especial das funções públicas, das leis e, por consequência, do Estado.

Originariamente destinada a combater a corrupção e o nepotismo, herança da visão patrimonialista, pode-se afirmar, a burocracia brasileira fomentou esses dois males que, ab ovo, propunha combater. Tanto é assim, que todos os consectários do patrimonialismo remanescem na gestão pública brasileira, como, aliás, já constatou, em sede doutrinária, a eminente ministra do Supremo Tribunal Federal Cármem Lúcia Antunes Rocha (1997:231):

O patrimonialismo na gestão da coisa pública; o personalismo na Administração Pública; o mandonismo na prática dos governos; o familiarismo no provimento dos cargos que teriam que ser públicos (e o são na nomenclatura legal), mas que são particularmente, fraternal ou amistosamente, guardados; todos os fatores, enfim, que tornam a res que deveria ser pública, tão 
pouco do povo substancialmente, impessoalmente, respeitosamente tratado, ainda estão presentes na prática administrativa brasileira.

Corrobora tal assertiva, igualmente, a necessidade de "recente" intervenção judicial - 21 de agosto de 2008 - para, em observância ao princípio constitucional da moralidade administrativa (art. 37, caput, CF), lançar mão de derradeira tentativa de banir o nepotismo do serviço público nacional: a edição, pelo egrégio Supremo Tribunal Federal, da Súmula Vinculante $n^{0} 13$. O enunciado da referida súmula se encontra assim redigido:

A nomeação de cônjuge, companheiro ou parente em linha reta, colateral ou por afinidade, até o terceiro grau inclusive, da autoridade nomeante ou de servidor da mesma pessoa jurídica investido em cargo em comissão de direção, chefia ou assessoramento ou, ainda, de função gratificada na administração pública em qualquer dos Poderes da União, dos Estados, do Distrito Federal e dos Municípios, compreendido o ajuste mediante designações recíprocas, viola a Constituição

\section{Reforma do Estado gerencialista e Emenda Constitucional no 19: um modelo em vigor, incompleto e assistemático}

As sucessivas "reformas administrativas" do aparelho estatal brasileiro, algumas meramente formais - como a de 1936, instituída na vigência da Constituição de 1934 e outras que promoveram, mesmo que principiologicamente, inovações na gestão da coisa pública - reforma de 1967 e aquela introduzida pela Emenda Constitucional no 19/98, não acarretaram no mundo dos fatos a desejada moralização e modernização da máquina estatal, afastando a administração pública brasileira do desiderato maior de promoção do "bem comum", para citar a terminologia clássica de Hely Lopes Meirelles (1997).

O chamado modelo gerencial não tem contornos bem definidos na gestão pública nacional até os dias de hoje, sendo possível identificar manifestações isoladas convivendo com as demais modelagens, agregando características assistemáticas à administração pública pátria, por meio da ausência do desejável atributo da coerência interna. Note-se que o gerencialismo, em sede de estudos de gestão pública, é alvo de severas críticas na literatura, principalmente, por não ter sido bem-sucedido na abordagem da dimensão sociopolítica e por colocar de lado a democratização do Estado brasileiro, privilegiando as suas características centralizadoras e autoritárias. 
A implantação da visão empreendedora no setor público se arrasta desde 1995, com alterações delineadas pelo plano diretor da reforma do aparelho do estado e tem como objetivo a busca da reorientação da ação estatal em direção à qualidade dos serviços prestados ao cidadão (Santos, 2003). A abordagem gerencialista (conhecida como "nova administração pública" e, até certo ponto ligada ao "movimento reinventando o governo") tem buscado a transferência da lógica, valores e práticas da administração de empresas para o setor público e tem suas bases teóricas no pensamento neoliberal e na teoria da escolha pública. Daí porque também é conhecida como modelo (ou abordagem) empreendedor(a).

O neoliberalismo tem seus antecedentes históricos remotos nas teorias do economista britânico Adam Smith, pai do liberalismo, segundo o qual as funções do Estado seriam basicamente três:

manutenção da segurança interna e externa;

garantia do cumprimento dos contratos;

prestação de serviços essenciais de utilidade pública. O Estado interviria o mínimo possível nas relações econômicas, permitindo uma autorregulação e adaptação naturalmente ocasionadas pela própria dinâmica liberalizada da economia (laissez faire, laissez passez).

As teorias de Smith foram revisadas ao longo da história, em primeiro lugar, por John Maynard Keynes, que teve impacto pragmático de suas teses econômicas na confecção do new deal promovido pelo então presidente estadunidense Theodore Roosevelt, diante do caos econômico ocasionador do desequilíbrio financeiro e do crash da Bolsa de Nova York, bem como pelas experiências realizadas pelos governos europeus no pós-guerra. Apregoava o economista, em análise macroeconômica, a necessidade da intervenção estatal e dos gastos governamentais ligados, portanto, à promoção do bem-estar social.

Por sua vez, a chamada escola de Chicago inaugurou uma corrente de pensamento diferenciada, que estabeleceu uma abordagem empírica para o neoliberalismo: o monetarismo. Segundo essa concepção, os governos deveriam abandonar as medidas keynesianas e adotar o controle monetário para evitar a inflação e a recessão econômica. Um dos seus expoentes, Milton Friedman, recupera as teorias neoclássicas e critica ferozmente as políticas de subsídios, os incentivos fiscais e registra os inconvenientes dos programas assistenciais relativos à saúde, à seguridade social etc., por interferirem demasiadamente nas opções individuais.

Paralelamente à escola de Chicago, os teóricos da escolha pública se incumbiram de elaborar críticas à burocracia. Para alguns pensadores, como Niskaken, a escassez de competição e de orientação para o lucro impediria que os burocratas 
usassem eficientemente as informações para a solução dos problemas administrativos. Surgiu, então, a ideia de remoção da burocracia pública da prestação de serviços públicos que poderiam ser mais bem realizados pela iniciativa privada, em condições de livre mercado. Tal abordagem justifica, teoricamente, as privatizações, terceirizações e criação de agências executivas típicas do modelo gerencialista (Paula, 2005).

O gerencialismo na administração pública teve grande repercussão na década de 1980, especialmente nos governos britânico (Margaret Thatcher e John Major) e estadunidense (Ronald Reagan e George Bush - "o pai" ) e foi propiciado pelo alinhamento entre a prática de tais políticos aos chamados think tanks vigentes à época, além da crise do fordismo, modelo que conectava, até então, a produção e o consumo por meio da garantia da acumulação capitalista e da utilização de máquinas, e da social-democracia (welfare state), base do modelo intervencionista estatal que foi questionada pelos neoliberais (Paula, 2005).

Surge, então, uma nova cultura gerencial que apregoa um modelo pós-fordista de trabalho e produção, e que defende o enxugamento das empresas, o crescimento das pequenas unidades produtivas, formatação de contratos flexíveis de trabalho. Surgem, paralelamente, as chamadas panaceias apregoadas pelos "gurus" da administração e que se apresentam como solução para os problemas de produção, sem maior comprometimento com os aspectos metodológicos e teóricos, como a reengenharia e a qualidade total. A nova cultura gerencial no setor público se apoiava a partir de 1987, em grande parte, no discurso de Young de defesa do empreendedorismo como um aspecto desejável e natural da personalidade humana e da ideia de que o empreendedorismo comunitário poderia substituir as provisões sociais do welfare state por iniciativas não lucrativas e de livre mercado.

A descentralização das atividades estatais, principalmente no modelo britânico, por meio da criação de agências executivas e da terceirização de serviços públicos, favoreceu a formulação de políticas governamentais pelas agências executivas e os terceiros contratados, dependendo da natureza do serviço público prestado (essencial ou não essencial). Ao mesmo tempo, o novo modelo procedeu à privatização stricto sensu de áreas que até então eram consideradas estratégias, como nos setores do carvão e do transporte aéreo, bem como à flexibilização das relações trabalhistas.

Nesse contexto, Paula (2005) lista as principais características da nova administração pública:

descentralização do aparelho do Estado, que separou as atividades de planejamento e execução do governo e transformou as políticas públicas em monopólio dos ministérios e secretarias de estado;

privatização das estatais; 
terceirização dos serviços públicos;

regulação estatal das atividades públicas conduzidas pelo setor privado;

uso de ideias e ferramentas gerenciais advindas do setor privado. Além dessas, elencamos como traço característico do gerencialismo o chamado ajuste fiscal, que teve, no Brasil, seu marco relevante com a edição da Lei Complementar no 101, de 4 de maio de 2000 (Lei de Responsabilidade Fiscal) e, que apesar de algumas inconstitucionalidades apontadas pelos juristas (Siraque, 2005), trouxe inovações interessantes para o modus operandi do administrador público no país.

As práticas da nova administração pública se espalharam pelo mundo, especialmente em países de origem anglo-saxônica, como a Austrália e a Nova Zelândia, valendo registrar a experiência desse país com outra ferramenta gerencial, conhecida como accountability, com razoável sucesso e repercussão acadêmica (Campos, 1990; Matias-Pereira, 2008).

Além da influência neoliberal e da teoria da escolha pública, como mencionado, propiciaram a reforma do Estado no Brasil na década de 1990 a crise do nacional-desenvolvimentismo e a ascensão do desenvolvimento dependente e associado, além da influência direta de organismos financeiros internacionais (FMI, BID e Bird) por meio do Consenso de Washington, conclusão extraída de uma reunião realizada na capital dos Estados Unidos da América onde, através da avaliação das medidas econômicas realizadas em países como México e Chile, entendeu-se pela procedência das reformas estatais voltadas para o mercado. Foi no governo Collor que teve início a adesão brasileira às recomendações "consensuais" para a crise latino-americana elaboradas pelos organismos internacionais supracitados, alguns economistas e representantes do governo estadunidense.

Como marco legal desse processo tem-se a promulgação da Emenda Constitucional $\mathrm{n}^{\mathrm{o}}$ 19, que teve como base os estudos desenvolvidos por Luiz Carlos Bresser-Pereira, que à época era ministro do Ministério da Administração Federal e Reforma do Estado (Mare). O principal responsável pela reforma consolidou boa parte de seus posicionamentos na obra reforma do Estado para a cidadania (1998), sendo que ela possuiria três dimensões: a institucional, a cultural e a gestão. Segundo o ilustre professor, as atividades estatais englobariam dois tipos básicos:

atividades exclusivas do Estado, como a legislação, regulação, fiscalização, fomento e formulação de políticas públicas, e pertenceriam ao núcleo estratégico do Estado composto pela Presidência da República e os 
ministérios, sendo realizadas pelas secretarias formuladoras de políticas públicas, agências executivas e agências reguladoras;

atividades não exclusivas do Estado que englobariam atividades de caráter competitivo, auxiliares e de apoio, incluindo entre elas serviços sociais (saúde, educação, assistência social) e científicos que seriam prestados tanto pela iniciativa privada quanto pelas organizações sociais. Por sua vez, as atividades reputadas como auxiliares, como limpeza, transporte, manutenção, serviços técnicos seriam submetidas à licitação pública e terceirizadas.

Nesse contexto, as atividades exclusivas do Estado seriam desempenhadas pelas agências executivas que, na realidade, seriam as autarquias e fundações assim qualificadas por gozarem de um regime jurídico especial previsto nos Decretos no 2.487 e no 2.488, ambos de 2 de fevereiro de 1998, e que dependeriam da celebração de contrato de gestão com o Ministério Supervisor, a que a entidade se achasse vinculada e da elaboração de plano estratégico de reestruturação e desenvolvimento institucional, voltado para a melhoria da qualidade de gestão e para a redução de custos. A Emenda Constitucional nº 19/98 também viabilizou a hipótese desses contratos serem celebrados no âmbito da própria administração direta, entre dirigentes de órgãos integrantes da mesma pessoa jurídica.

O fim último dos contratos de gestão seria a eficiência, princípio constitucional insculpido no art. 37, caput, da Carta Maior. O ajuste deveria conter, no mínimo:

a forma como a autonomia deve ser exercida;

metas a serem cumpridas pelo órgão ou entidade no prazo estabelecido no contrato;

controle do resultado.

A doutrina aponta fragilidade jurídica nesse instituto quando celebrado com órgão da administração direta à medida que um contrato pressupõe acordo de vontades entre pessoas dotadas de capacidade (titularidade de obrigações e direitos), o que é inviável em se tratando de órgãos da administração direta que não são dotados de personalidade jurídica, mas atuam em nome da pessoa jurídica em que estão integrados, o que acarreta contratação entre dois signatários que representam a mesma pessoa jurídica e que, por razões óbvias, não podem ter interesses contrapostos defendidos por órgãos diversos. Da mesma forma, a hipótese de contrato de gestão firmado entre administração indireta e poder público carece de característica geral dos contratos da existência de interesses opostos e contraditó- 
rios, não se podendo conceber diversidade ontológica de interesses entre administração direta e indireta (Di Pietro, 1999).

Outros institutos criados pela Emenda Constitucional no 19/98 são as agências reguladoras que têm como finalidade a regulação e o controle das atividades transferidas ao particular pelo Estado, por meio de concessão, permissão e autorização de serviço público e integram a administração indireta sob a forma de autarquias especiais, vinculadas ao ministério, que corresponda à respectiva área de atuação, sendo que sua criação deve ser feita por meio de lei específica. A doutrina aponta que tais pessoas jurídicas, em que pese fazer parte da administração indireta e estar vinculadas a um ministério, gozam de independência funcional e financeira (Paes, 2006). São agências reguladoras a Agência Nacional do Petróleo (ANP), Agência Nacional de Telecomunicações (Anatel), Agência Nacional de Energia Elétrica (Aneel), Banco Central (BC) e Conselho Administrativo de Defesa Econômica (Cade).

No campo das atividades não exclusivas do Estado, a terceirização das atividades auxiliares ou de apoio, como mencionado, se baseia nas regras relativas à licitação. Por outro lado, para as atividades de caráter competitivo, ou seja, aquelas que poderiam ser prestadas tanto pelo setor público quanto pelo privado, surgiu nova figura denominada organizações sociais (OS).

Segundo Paes (2006:452):

As organizações sociais objetivam ser um modelo de parceria entre o Estado e a sociedade, mas não constituem uma nova pessoa jurídica; inserem-se no âmbito das pessoas jurídicas já existentes sob a forma de fundações, associações civis e sociedades civis, todas sem fins lucrativos. Portanto, elas estão fora da Administração Pública, pois são pessoas jurídicas de direito privado. [...]

Qualificada como Organização Social, a entidade-fundação, associação ou sociedade estará habilitada a receber recursos financeiros e a administrar bens e equipamentos, e pessoal do Estado. Em contrapartida, para a formação dessa parceria, a OS se obriga a firmar um contrato de gestão com o Poder Público, por meio do qual serão acordadas metas de desempenho que assegurem a qualidade e a efetividade dos serviços prestados ao público.

As organizações sociais são fruto da Lei nº 9.637, de 15 de maio de 1998, que além de ser omissa em alguns pontos como, por exemplo, quando deixa de incluir entre os requisitos listados no seu art. $2^{\underline{0}}$ a impossibilidade de atuação das OS em atividades estranhas ao seu estatuto e às referidas no art. $1^{\circ}$ do mesmo diploma legal (Paes, 2006), é considerada por boa parte da doutrina como totalmente ou parcialmente inconstitucional. 
Vale registrar ainda, que a Lei no 9.790, de 23 de março de 1999, disciplinou as denominadas Organizações da Sociedade Civil de Interesse Público (Oscips), que são pessoas jurídicas de direito privado sem fins lucrativos que compõem o terceiro setor e, assim como as OS, dependem de uma qualificação pelo poder público com quem se relaciona por meio da parceria (instrumentalizado pelo chamado "termo de parceria"), estabelecendo um vínculo jurídico de cooperação. As Oscips, segundo determina o art. $3^{\circ}$ e incisos do mencionado diploma legal, devem atender ao princípio da universalização dos serviços e apresentar em suas finalidades ou objetivos estatutários:

promoção da assistência social;

promoção da cultura;

defesa e conservação do patrimônio histórico e artístico;

promoção gratuita da educação e da saúde, observando-se a forma complementar de sua participação, nos termos da lei;

promoção da segurança alimentar e nutricional;

defesa, preservação e conservação do meio ambiente, e promoção do desenvolvimento sustentável;

promoção do voluntariado;

promoção do desenvolvimento econômico e social, e combate à pobreza;

experimentação, não lucrativas, de novos modelos socioprodutivos e de sistemas alternativos de produção, comércio, emprego e crédito;

promoção de direitos estabelecidos, construção de novos direitos e assessoria jurídica gratuita de interesse suplementar;

promoção da ética, da paz, da cidadania, dos direitos humanos, da democracia e de outros valores universais;

estudos e pesquisas, desenvolvimento de tecnologias alternativas, produção e divulgação de informações e conhecimentos técnicos e científicos.

Com as Oscips se criou mais uma figura na administração pública, com regramentos próprios e com gerenciamento de verbas públicas repassadas à pessoa jurídica de direito privado e que, mais uma vez, interagia em um sistema já fragmentário e de difícil e onerosa fiscalização e controle (Paula, 2005). Mesmo que 
bem intencionada, no plano do dever ser, e com relevantes casos de "sucesso", atendimento dos requisitos e cumprimento de seus deveres legais, inúmeros têm sido os questionamentos judiciais partindo do órgão do Ministério Público, com a propositura dos mais diversos tipos de ações para combater a perpetração da ilegalidade na administração pública, buscando a responsabilização penal, civil e de improbidade por desvios e malversação de verbas públicas. ${ }^{3}$

\footnotetext{
${ }^{3}$ Cite-se, como exemplo de fraude perpetrada no âmbito do poder público, no ente federado Distrito Federal, o conhecido "caso" do Instituto Candango de Solidariedade (ICS), em que, entre outras coisas, o Ministério Público do Distrito Federal, Ministério Público de Contas do Distrito Federal, Ministério Público do Trabalho e Ministério Público Federal constataram violação à legislação afeta às licitações (Lei $n^{\circ}$ 8.666/93) e à própria qualificação do ICS como organização social, em detrimento do patrimônio público. A decisão proferida pelo Superior Tribunal de Justiça abaixo transcrita ilustra parcialmente a problemática trazida por essa nova organização instituída pela reforma gerencialista (Recurso Especial no 885.523 - DF (2006-0149013-7). Recorrente: Ministério Público do Distrito Federal e Territórios. Recorrido: Distrito Federal. Relator: Ministro Castro Meira. A decisão seguiu assim ementada: "PROCESSUAL CIVIL E ADMINISTRATIVO. CONTRATO DE GESTÃO. VIOLAÇÕES DOS ARTS. $1^{\circ}$ DA LEI № 1.533/51, 301, PARÁGRAFOS $1^{\circ}$ A $3^{\circ}$ 을 CPC E 24, INC. XXIV DA LEI № 8.666/93. OCORRÊNCIA DE LITISPENDÊNCIA. IRREGULARIDADES NA QUALIFICAÇÃO DO INSTITUTO CANDANGO DE SOLIDARIEDADE COMO ORGANIZAÇÃO SOCIAL. DESOBEDIÊNCIA A DETERMINAÇÕES DO TRIBUNAL DE CONTAS DO DISTRITO FEDERAL NO EXERCÍCIO DO CONTROLE EXTERNO. NÃO OCORRÊNCIA DOS PRESSUPOSTOS PARA CONCESSÃO DE SEGURAÇA EM AÇÃO MANDAMENTAL. DESRESPEITO À LEI DE LICITAÇÕES.

1. Configurada a litispendência (ofensa ao art. 301 , parágrafos $1^{\circ}$ ao $3^{\circ}$ do $C P C$ ), visto serem as mesmas partes (o ICS e o Tribunal de Contas do Distrito Federal - TCDF), o mesmo pedido (desconstituição de decisões do TCDF) e a mesma causa de pedir (qualificação do ICS como organização social, prevista na Lei Distrital no 2.415/99). Violação que se constata, pois todas as decisões do CDF hostilizadas no writ n⿳o 2003.00.2.009144-8 e 2003.00.2.011424-6 versam sobre o mesmo objeto.

2. Descumprimento, pelo Instituto Candango de Solidariedade, dos requisitos legais insculpidos no art. 24, XXIV, da Lei no 8.666/93, que prevê dispensa de licitação 'para a celebração de contratos de prestação de serviços com as organizações sociais, qualificadas no âmbito das respectivas esferas de governo, para atividades contempladas no contrato de gestão'.

3. Não ocorre direito líquido e certo que justifique a concessão da segurança. Conquanto o pedido no mandamus fosse a desconstituição de decisões supostamente ilegais, na verdade, o que se objetivava era o afastamento da fiscalização realizada pelo Tribunal de Contas do Distrito Federal sobre os contratos administrativos. Almejou-se o inexistente direito líquido e certo de não ser fiscalizado, obrigação à qual nenhum ente se pode furtar.

4. Recursos especiais providos "Por sua vez, a celebração de termo de parceria com a Fundação Zerbini deu ensejo a pelo menos uma ação civil pública de controle, por nós proposta quando de passagem pela Promotoria de Defesa da Saúde (Prosus)(Processo no 2005.01.1.033980-0, distribuído à Oitava Vara de Fazenda Pública) em que se obteve provimento jurisdicional liminar e final favorável na primeira instância, em grande parte confirmada na segunda instância, conforme decisão que seguiu assim ementada (Apelação cível - Remessa ex offício 20050110339800APC. Primeira Turma Cível. Apelante: Distrito Federal. Apelado: Ministério Público do Distrito Federal e Territórios. Relator: Des. Nívio Geraldo Gonçalves. Acórdão no 295.937): “CONSTITUCIONAL. ADMINISTRATIVO. PROCESSUAL CIVIL. AÇÃO CIVIL PÚBLICA. DISTRITO FEDERAL. FUNDAÇÃO ZERBINI. TERMO DE PARCERIA. NULIDADE. POSTERIOR CELEBRAÇÃO DE CONVÊNIO. PREVALÊNCIA DO INTERESSE DE AGIR DO MINISTÉRIO PÚBLICO. CONSECUÇÃO DO PROGRAMA FAMÍLIA SAUDÁVEL. REPASSE CONSIDERÁVEL DE RECURSOS PÚBLICOS. CONCURSO DE PROJETOS. NECESSIDADE. PRINCÍPIO DA IMPESSOALIDADE. SENTENÇA MANTIDA.

I - Em que pese ter sido celebrado Convênio após finalizado o Termo de Parceria, não há falar em perda superveniente do interesse de agir, que dê azo à extinção do feito com fulcro no art. 267, inc. IV, do CPC, uma vez que o objeto principal da lide é a declaração da nulidade do Termo de Parceria precedente, desde o seu início, a surtir, portanto, efeitos pretéritos à celebração do Convênio.

II - À luz da Constituição Federal, não se pode conceber que organizações não lucrativas, que venham a assumir temporariamente a qualificação de OSCIP, estejam livremente autorizadas a receber considerável repasse de recursos públicos, sem se submeterem a qualquer procedimento licitatório.
} 
Boa parte da literatura da administração pública aponta para críticas ao modelo gerencial e suas figuras centrais (agências executivas, agências reguladoras e organizações sociais), indicando em seus estudos, para a fragmentação do aparelho do Estado e para a ausência da preconizada eficiência na prestação dos serviços públicos (Paula, 2005:73):

\begin{abstract}
A nosso ver, apesar de ter um projeto bem definido para a mudança institucional, a reforma acabou causando uma fragmentação do aparelho do Estado, pois os novos formatos organizacionais sugeridos pela reforma não substituíram os antigos: há uma convivência de ambos. Nem todas as autarquias e fundações públicas se transformaram em agências executivas e várias entidades da sociedade civil iniciaram o processo de conversão em organizações sociais, mas acabaram optando pelo antigo status institucional. [...]
\end{abstract}

III - Conquanto o caput do art. 23 do Decreto nº 3.100/99 preveja que 'poderá' a escolha da Organização da Sociedade Civil de Interesse Público, para a celebração do Termo de Parceria ser feita por meio de publicação de edital de concursos de projetos pelo órgão estatal parceiro para obtenção de bens e serviços e para a realização de atividades, eventos, consultorias, cooperação técnica e assessoria, traduzindo, a princípio, a ideia de conveniência e oportunidade, em verdade, diante do motivo de relevante interesse social que enseja a celebração do Termo de Parceria, não há mera faculdade atribuída ao Administrador, mas sim o dever de se proceder ao processo seletivo.

IV - Em honra ao princípio constitucional da impessoalidade, que rege a Administração Pública, existindo a previsão de repasses vultosos de recursos públicos para o fomento de serviço de interesse social, afigura-se imprescindível a realização de concurso de projetos que legitime o Poder Público a celebrar Termo de Parceria com Organização da Sociedade Civil de Interesse Público.

V - Não cabe ao Poder Judiciário determinar quando deve a Administração realizar a consecução de políticas públicas, cabendo-lhe, tão somente, manifestar-se quanto ao aspecto da ocorrência de ilegalidade ou de abuso de poder". A parte final da jurisprudência será bastante questionada, conforme registros ao longo do nosso trabalho.

Vale registrar ainda a repulsa exercida judicialmente aos atos inconstitucionais e ilegais perpetrados pelo ICS por meio de ação civil pública proposta pelo Ministério Público do Trabalho, que enxergou no merchandage (intermediação de mão de obra por pessoa interposta) como uma prática ilegal dentro da administração pública do Distrito Federal, em que, por meio da simulação, se lança mão de expediente fraudulento para a contratação de mão de obra, sem a observação da regra vinculante do concurso público (art. 37, inc. II, CF). Segue ementa da decisão proferida pelo Tribunal Regional do Trabalho da 10ª Região (Acórdão, 1를 Turma, TRT 01293-2005-020-10-00-5, Recurso Ordinário, 2006): “ADMINISTRAÇÃO PÚBLICA. MERCHANDAGE. ILEGALIDADE. A prática do merchandage (intermediação de mão de obra por pessoa interposta) no âmbito da Administração Pública é ilícita, seja para a prestação de atividade-fim ou atividade-meio. Ressalvam-se, apenas, o trabalho temporário e os serviços em atividades-meio sem pessoalidade e subordinação (Súmula no 331 do TST). O contrato de trabalho é negócio jurídico bilateral apto a produzir os efeitos previstos em lei e os acordados pelas partes. Tratase de instituto jurídico objeto de intensa normatização, em especial no plano constitucional. Entretanto, instituto de tal envergadura não pode ser instrumento de fraude, de precarização do trabalho humano e de sonegação fiscal. No caso vertente, os contratos de trabalho discutidos foram utilizados como instrumentos de uma simulação. Utilizou-se a exterioridade de um instrumento lícito para a consecução de objeto ilícito. Usou-se do contrato de trabalho como meio de burla. Trata-se de verdadeira farsa, na qual se dissimula um comportamento aberrante da Administração, contrária à regra vinculante do concurso público (CF, art. 37, inc. II)"'. 
Na realidade, o projeto das agências executivas e das organizações sociais não alcançou a extensão esperada e isso impossibilitou que o aparelho de Estado fosse redesenhado a partir de uma matriz mais definida de organização e gestão dos órgãos da administração pública. [...] No entanto, as últimas vêm encontrando dificuldades em relação ao alcance de níveis satisfatórios de eficiência e atendimento do interesse público. Com frequência, os diretores da ANP, Aneel e Anatel fazem declarações à imprensa sobre as dificuldades de regulação dos órgãos sob sua administração e os cidadãos se queixam das limitações das agências na fiscalização da prestação de serviços públicos.

Outra crítica recorrente ao gerencialismo na administração pública reside no fato de que existe, por força constitucional, uma verdadeira adstrição do Estado à prestação de serviços públicos como, por exemplo, os de saúde. Nesse sentido, aos parceiros da iniciativa privada na área de saúde, conforme estabelecem os arts. 24 e 26 da Lei no 8.080, de 19 de setembro de 1990 ("Lei do Sistema Único de Saúde - SUS") incumbe, tão somente, um papel complementar só admissível quando as disponibilidades do SUS "forem insuficientes para garantir a cobertura assistencial à população de uma determinada área". Essa ideia de complementaridade denota, antes de mais nada, que a prestação do serviço público deve estar subordinada a um regime jurídico de direito público (Di Pietro, 1999:173-175).

Há, portanto, uma equivocada tendência no sentido de trasladar a titularidade e o exercício de algumas atividades para pessoas jurídicas de direito privado, de forma contrária ao determinado na Lex Mater. No Brasil, esse fenômeno foi alavancado quando da elaboração do plano diretor de reforma do aparelho do Estado, em 1995, ocasião em que ficou definido que, pelo processo de publicização, busca-se transferir para o setor público não estatal serviços não exclusivos do Estado, como saúde e educação, por exemplo, com a respectiva burla às regras da licitação e do concurso público, que, por terem assento constitucional, têm eficácia subordinante somente afastável em hipóteses excepcionais.

Com relação à ausência de licitação, observa Celso Antônio Bandeira de Mello (2009:215):

Há nisto uma inconstitucionalidade manifesta, pois se trata de postergar o princípio constitucional da licitação (art. 37, XXI) e, pois, o princípio constitucional da isonomia (art. $5^{\circ}$ ), do qual a licitação é simples manifestação punctual, conquanto abrangente também de outro propósito (a busca do melhor negócio). Não se imagine que pelo fato de o art. 37, XXI, mencionar a obrigatoriedade da licitação, salvo nos casos previstos em lei, o legislador é livre para arredar tal dever sempre que lhe apraza. Se assim fosse, o princípio não teria envergadura constitucional. 
Mas, no nosso entender, a principal fragilidade da "nova administração pública" está no fato de que ela não democratizou a gestão da coisa pública.

Note-se que algumas das principais discussões acadêmicas e práticas levadas a efeito pela administração pública gerencial são plenamente aceitas pelo direito, havendo mesmo correlação de visões e interesses comuns. Nesse diapasão, a necessidade de maior transparência no setor público e da vinculação do gestor público à prestação de contas, a eficiência da máquina estatal e da qualidade na prestação do serviço público são preocupações tanto do jurista quanto do estudioso da gestão pública. ${ }^{4}$

Não se pode, contudo, negar a existência de "pontos de tensão" entre o direito e a administração pública pautada nos estudos bresser-pereirianos, "pai" do gerencialismo brasileiro. Algumas das ferramentas gerenciais são consideradas por boa parte dos doutrinadores como inconstitucionais, a exemplo das organizações sociais, e se constituem em importações e manifestação de um neocolonialismo e neoliberalismo em sede de direito administrativo (Mello, 2009). Outros institutos importados do direito alienígena, como as agências reguladoras, são questionados na medida em que vêm sendo criados por meio de lei que lhes confere poder autônomo de baixar normas, o que é constitucionalmente vedado à medida que o poder regulamentar é privativo do chefe do Poder Executivo e não haveria espaço no direito administrativo brasileiro para os decretos ou regulamentos autônomos (contudo, aceitáveis no âmbito do direito francês e estadunidense), onde as agências têm um funcionamento mais qualificado dos contratos de gestão, que se adaptam mal à rigidez do regime legal-administrativo pátrio e, muito por isso, são objetos de inúmeros desvios relativos ao enriquecimento ilícito, prática de atos lesivos ao patrimônio público ou atentatórios aos princípios regentes da atividade estatal, exemplos das reiteradas burlas à regra do concurso público (art. 37, II, CF) e malversação do dinheiro público (Garcia e Alves, 2004).

Outra questão importante diz respeito à ausência de compatibilidade de algumas ferramentas da administração de empresas, de lógica empresarial, ao direito administrativo, em pouco consistente transplantação. Evoque-se o exemplo da "qualidade total", que com seus limitados conceitos (do tipo: "cidadãos" como "clientes"), não corresponde de forma absoluta à concepção jurídica do tipo "ci-

\footnotetext{
${ }^{4}$ Veja o exemplo da accountability, que tem correspondência transdisciplinar (Piaget e Bertallanffy) com o princípio da transparência da administração pública, e no Brasil decorre de normas constitucionais e legais expressas ou implícitas, recebendo o apoio da doutrina e jurisprudência (Di Pietro, 2009). O próprio ministro Joaquim Barbosa do egrégio STF já mencionou em suas manifestações na Corte Suprema o denominado "princípio da accountability", merecendo aqui registro duas referências jurisprudenciais: 1. Mandado de Segurança no 25.181-6. Ementário no 2237-1. Publicado no DJ de 16 jun. 2006. Relator ministro Marco Aurélio. Tribunal Pleno. 2. Medida Cautelar em Mandado de Segurança no 24.832-7, DF. Relator ministro Cezar Peluso. DJ de 18 ago. 2006. Ementário no 2243-1. Tribunal Pleno.
} 
dadão" como "credor", ligada ao ideário dos direitos positivos, e como gestor, ideário imbricado aos novos direitos, ligados à realização plena da democracia.

Outra ilegalidade, prontamente constatável na literatura que trabalha essa técnica gerencialista, está na sua distância conceitual para a contemporânea concepção política e jurídica: a do cidadão credor. Também, por total incompatibilidade legal, não se pode conceber no sistema jurídico em vigor a aplicação de regras de direito do consumidor ao Poder Judiciário, como, aliás, já tentou vislumbrar Carmen Luiza Dias Azambuja e José Jerônimo de Menezes Lima em obra intitulada Judiciário: qualidade total (1999).

Não se quer aqui negar a importância das discussões acerca de qualidade e que assolam o Ministério Público e o Poder Judiciário, e os respectivos conselhos nacionais do Ministério Público e da Justiça, órgãos de controle externo do Ministério Público e do Poder Judiciário (importante medida nessa direção se verifica na Recomendação no 14 , de 17 de novembro de 2009, do CNMP), ${ }^{5}$ tudo isso com o especial objetivo de dar cumprimento ao princípio da duração razoável do processo, insculpido no art. 5ª , inciso LXXVIII, da Lei Maior.

Quer-se apenas apontar para a existência de vertentes gerencialistas pouco comprometidas com a noção de interesse público e com as concepções básicas de cidadania e de conformação estatal. Apregoam, sem maiores considerações teóricas, a transposição de técnicas do setor privado para o público, em flagrante violação à legislação em vigor e com o uso de nomenclatura equivocada. ${ }^{6}$

\footnotetext{
5 “RECOMENDAÇÃO № 14, de 17 de novembro de 2009. Dispõe sobre o apoio institucional do Conselho Nacional do Ministério Público ao cumprimento da Meta de Nivelamento no 2, do Poder Judiciário, para o ano de 2009.

O CONSELHO NACIONAL DO MINISTÉRIO PÚBLICO, no exercício das atribuições conferidas pelo art. 130-A, §2º inc. I, da Constituição da República, e no art. 31, inc. VIII, do seu Regimento Interno, em conformidade com a decisão plenária tomada em sessão realizada no dia 17 de novembro de 2009; CONSIDERANDO a importância do planejamento estratégico como instrumento de gestão para o aprimoramento das atividades e o alcance pleno da missão do Poder Judiciário, na realização da Justiça; CONSIDERANDO que a adoção da Meta de Nivelamento ํำ 2, por todo o Poder Judiciário Nacional, voltada à identificação dos processos ingressados em cada uma das instâncias até 31/12/2005 e a adoção de providências concretas para o respectivo julgamento neste ano de 2009 é medida de grande potencial de efetividade, na concretização da garantia constitucional da razoável duração do processo (art. 5o, LXXVIII, da CF);

CONSIDERANDO que é fundamental, para o alcance de metas desta natureza, a atuação integrada de todos os órgãos essenciais à Justiça, especialmente o Ministério Público;

RESOLVE:

Recomendar aos ramos do Ministério Público da União e dos Estados, na pessoa dos respectivos Procuradores-Gerais, em comum acordo com o Poder Judiciário local, e sem prejuízo do atendimento das próprias metas e prioridades, a adoção de medidas concretas, no âmbito de sua competência, para viabilizar o atingimento da Meta de Nivelamento no 2, do Poder Judiciário, para o ano de 2009.

Brasília, 17 de novembro de 2009.

ROBERTO MONTEIRO GURGEL SANTOS

Presidente do Conselho Nacional do Ministério Público."

${ }^{6}$ Por outro lado, apontamos também para a existência de alguns estudos merecedores de aplausos.

É o caso daqueles realizados no âmbito do próprio Ministério Público (no caso, o Ministério Público
} 
O próprio conceito de empreendedorismo precisa ser formatado de acordo com cada setor: o público e o privado. Essa tal concepção está ligada às ideias de criatividade e decorre de sua própria natureza mais dinâmica e que visa, insofismavelmente, aos resultados e lucros, mesmo que, em algumas hipóteses, se perceba o comprometimento com a denominada responsabilidade social. ${ }^{7}$ Naquele exigível é a sua conformação à Constituição Federal e demais leis, sua adstrição aos regramentos legais relativos à prática dos atos administrativos. Pensamos, contudo, ser indispensável buscar o equilíbrio para que não se extirpe do gestor a raiz de inovação, tão importante na seara pública quanto privada e que viabiliza a construção de novas posturas mais fluidas, sem que se vislumbre violação ao sistema legal, ou seja, atente contra o direito.

A própria literatura da administração pública aponta para a crise do modelo gerencialista no mundo desde o final dos anos 1990 e, mais recentemente, para sua superação. Em síntese, a avaliação crítica dos teóricos desse ramo do conhecimento diz respeito:

ao contrário do que propugnava academicamente a nova administração pública, que explicitou seu caráter centralizador da nova administração pública, que focou o poder decisório nos ministérios (e nas secretarias de Estado);

à ignorância de aspectos relativos à complexidade da gestão e que perpassam necessariamente por aspectos não apenas técnicos, mas políticos;

à supressão da dimensão sociopolítica e à manutenção do caráter autoritário do processo político;

à inadequação das técnicas utilizadas pela administração gerencial no setor público, transplantadas do setor privado sem maiores considerações de ordem prática e ordem legal;

à incompatibilidade entre a lógica gerencialista e o interesse público;

Federal), e publicados pela Escola Superior do Ministério Público da União, sob o título Estatística de qualidade no Ministério Público Federal: um ensaio. Deles se extrai a consistência dos dados estatísticos bem trabalhados e a compatibilidade conceitual utilizada na pesquisa com os institutos extraídos da Carta Magna, e demais legislação em vigor, exigência indeclinável quando o tema é administração pública (na hipótese, em sentido lato) e o tema da qualidade (Frischeisen e Moscogliato, 2008).

${ }^{7}$ Vale registrar como literatura de qualidade a ilustrativa coleção, da autoria de J. Marcovitch, que encerra valorosa pesquisa sobre personagens-empreendedores pátrios, a exemplo de visconde de Mauá, Ramos de Azevedo, Assis Chateaubriand e tantos outros: Pioneiros e empreendedores: a saga do desenvolvimento no Brasil, editada pela Edusp/Saraiva, referenciada ao final da dissertação. O empreendedorismo, na visão da administração, poderá ser uma resposta adequada à necessidade de se instalar um desenvolvimento sustentável no país, com melhor distribuição de renda e oportunidades sociais (equidade). 
à não redução dos custos governamentais com a formação de uma nova camada de burocratas;

às dificuldades e ao aumento de gastos com relação à fiscalização e controle do terceiro setor, com violação ao princípio da economicidade.

A experiência gerencialista se mostrou limitada e, em grande parte, incompatível com os pressupostos legais da administração pública, em que, como sabido, só pode o gestor público agir segundo o que a lei permite e prescreve, e a accountability, nesse sentido, deve se referir à responsabilidade e ao comprometimento do funcionário público em relação às restrições impostas em lei. Não se pode jamais esquecer a clássica lição de que enquanto na seara privada se permite tudo que não é vedado em lei, no setor público só é autorizada a realização do que é permitido em lei.

Os estudiosos ligados à nova administração pública enfatizam que para haver um aumento necessário da eficiência deveria aumentar a discricionariedade do administrador público e que os resultados obtidos deveriam ser avaliados após a tomada de decisão, ou seja, priorizando-se o controle de resultados (Di Pietro, 1999) em detrimento do a priori. Tais seriam, aliás, os pilares da gestão pública gerencialista bresser-pereiriana. De certa forma, percebe-se uma intenção de aumentar a área de atuação criativa e inovadora do gestor também importante para a solução dos conflitos sociais, mas que jamais poderia colocar em xeque a observância dos princípios constitucionais e do regramento infraconstitucional. O controle só de resultados é um ideal que pressupõe aprimoramento ainda não alcançado por nossa administração pública: o de possuir uma administração profissionalizada, em que a valorização do servidor público passa pelo respeito às regras constitucionais do concurso público, em detrimento das terceirizações, além de maiores investimentos em treinamento e desenvolvimento de pessoas (Hage, 2009).

A literatura da administração pública questiona a compatibilidade do funcionamento gerencial, de garantia de maior discricionariedade no atuar do gestor público (dita autonomia gerencial), e o interesse público, inclusive, criando neste uma postura individualista que facilita a corrupção. Nesse ponto, ensina Paula (2005:81):

No entanto, apesar da intenção de aumento da eficiência e dinâmica administrativa, essa lógica de funcionamento gerencial é incompatível com o interesse público, pois para assegurá-lo é preciso restringir o poder discricionário dos burocratas e também delimitar as responsabilidades gerenciais antes do processo de tomada de decisão. Por outro lado, há a dificuldade de conciliação entre os interesses dos gerentes públicos e as metas oficiais do 
governo, pois a excessiva autonomia dos administradores públicos tende a evoluir para uma posição individualista, que compromete a visão global e integrada de governo, além de aumentar os riscos de corrupção. Na verdade, o equilíbrio entre a autonomia gerencial e os interesses organizacionais continua desafiando o próprio setor privado. Por essas razões, os controles da ação gerencial estão sendo resgatados no Reino Unido e em outros países que adotaram a nova administração pública.

\section{Modelo social de administração pública: a estruturação da democracia deliberativa e sua compatibilidade constitucional}

De toda a tensão descrita supra surge a necessidade de se discutir um "novo" modelo de gestão pública, que se chamará, neste artigo, de pós-gerencial (social ou alternativa). A moderna gestão pública é societal, democrática e enfatiza a participação do corpo social no processo político e tem como fundamento três dimensões que, idealmente, deveriam se equilibrar (Paula, 2005:09):

a econômico-financeira, relacionada aos problemas financeiros e de investimentos estatais, e engloba questões de natureza fiscal, tributária e monetária;

a institucional-administrativa, que se relaciona com os problemas de organização e articulação dos órgãos estatais a exemplo das dificuldades de planejamento, direção, controle e profissionalização dos servidores públicos;

a sociopolítica, que abrange a problemática da relação Estado e sociedade, ou seja, os direitos dos cidadãos como um todo, e, especificamente, o de participar gestão da res publica.

A administração societal recebe, teoricamente, influências diretas de algumas visões de gestão, como a busca de um novo modelo de desenvolvimento, uma concepção participativa-deliberativa de democracia (bottom-up) que se agregue, de forma consistente e harmônica, à já estabelecida democracia representativa (topdown), à reinvenção político-institucional com a incorporação de gestão dialógica e não apenas monológica, bem como à renovação do perfil dos administradores públicos. Na prática, a experiência da gestão societal diz respeito ao funcionamento dos fóruns temáticos, conselhos gestores de políticas públicas, do orçamento participativo e da evolução do cooperativismo de trabalhadores, todos institutos em construção, como, aliás, parece também estar o próprio fenômeno de elaboração 
da administração pública. Ela transfere a soberania do Estado para a Constituição e por isso mesmo deve ser compreendida como a democracia constitucional, sendo, portanto, plenamente compatível com o sistema normativo em vigor no país.

Juridicamente, vige no Estado brasileiro um sistema bidimensional de democracia: a representativa e a direta. Entrementes, como bem aponta Paulo Bonavides, apenas a primeira, pela sua índole elitista e conservadora da classe política, compõe a dinâmica do governo. A outra, embora instituída também no plano constitucional, por meio do instituto da soberania popular e de suas subespécies participação popular e controle social, permanece adormecida, mesmo que componha a base principal que confere unidade à Constituição da República. Por isso, aponta o emérito constitucionalista (Bonavides, 2001:171-172):

Não se justifica, por conseguinte, que um deles - precisamente o da soberania popular, o mais excelso de todos na mecânica funcional do regime - fique assim proposto e inferiorizado respeitante às aplicações políticas de sua dimensão direta, o que equivaleria a mutilar o sistema constitucional de poder e a comprometer a legitimidade e o futuro da democracia no Brasil.

No direito constitucional positivo brasileiro, a democracia participativa se extrai do art. $1^{\circ}$, parágrafo único, segunda parte, da Carta Magna, que determina que todo o poder emana do povo, que o exerce por meio de representantes eleitos ou diretamente. Exsurgem, como desdobramentos dessa determinação principiológica, os direitos políticos da população que são definidos como o conjunto de regras que disciplina as formas de atuação da soberania popular, nos termos do que estatui o caput do art. 14 da Carta Magna e que, como bem ensina Alexandre de Moraes (2009), são direitos públicos subjetivos que investem o indivíduo no status actiavae civitatis, permitindo-lhe o exercício concreto da liberdade de participação nos negócios políticos do Estado, de maneira a conferir os atributos da cidadania (Moraes, 2009:227).

Dentro dessa concepção, temos como direitos políticos o direito de sufrágio, ${ }^{8}$ a alistabilidade, a elegibilidade, a iniciativa popular de lei, a ação popular, a organização e participação de partidos políticos, além de todos os mecanismos de controle social. ${ }^{9}$

\footnotetext{
${ }^{8} \mathrm{O}$ sufrágio universal é hipótese de accountability vertical.

9 O termo "controle social" é utilizado aqui no sentido de controle democrático, a exemplo daquele exercido pela sociedade civil. O orçamento participativo, por exemplo, é uma ferramenta de controle social que, mesmo que admirável por incutir um sentido dialógico no processo político, não está à margem de críticas, já que tem pequeno impacto na elaboração orçamentária, pois, segundo os analistas, o que resta do orçamento para investimentos em obras e infraestrutura, dentro da visão deliberativa, gira em torno de $1 \%$ do valor global.
} 
Note-se que o fortalecimento da democracia depende de um relacionamento equilibrado entre o poder público e a sociedade, de tal modo que o Estado não seja fortalecido em si e por si mesmo, isto é, em função dos fins que lhe são próprios, mas sim em razão das finalidades dos indivíduos, dos grupos naturais e da coletividade em seu conjunto. Necessário se faz superar o conceito de Estado como parte principis, privilegiando a concepção estatal ex parte populi (Bobbio, 2005).

A efetiva democratização política da administração pública, por meio da participação popular na gestão das políticas públicas, é uma realidade jurídica já normatizada no plano infraconstitucional.

Exemplifique-se a normatização do tema no ramo do direito sanitário que prevê três instituições básicas para o regular exercício da cidadania: as conferências (Lei Federal n⿳ำ 8.142/90, art. 1ํㅡ, I), os conselhos de saúde (Lei Federal nº 8.142/90, art. $1^{\circ}$, II) e os fundos de saúde (Lei Federal nº 8.142/90, art. $2^{\circ}$ ). Na esfera do direito ambiental, o art. $1^{\circ}$, inciso VI da Lei no 9.433/97 determina que a gestão dos recursos hídricos deve ser descentralizada e contar com a participação do poder público, dos usuários e das comunidades. Igualmente, a Lei no 10.257 , de 10 de julho de 2001 (Estatuto da Cidade), afeita mais especificamente ao meio ambiente artificial, determinou em seu art. 43 a gestão democrática da cidade por meio de: "I - órgãos colegiados de política urbana, nos níveis nacional, estadual e municipal; e IV - iniciativa popular de projeto de lei e de planos, programas e projetos de desenvolvimento urbano". O art. 43 integra três ideias que são centrais neste ensaio: participação popular, planejamento urbano e equidade intergeracional na medida em que preconiza a garantia de um meio ambiente (artificial) que propicie a sobrevivência digna da presente geração e das próximas gerações (ideia de equidade intergeracional). Por sua vez, no campo do direito educacional está claro que, no plano legislativo-dogmático, o Brasil adotou o ideário da reforma civil democrática, conforme se extraem da exegese:

do art. 53, incisos II e III do Estatuto da Criança e do Adolescente (ECA), que atribui aos filhos o papel de protagonistas do seu processo educacional na medida em que podem a todo tempo questionar os métodos pedagógicos empregados por seus pais e educadores;

do art. 206 da Constituição Federal e art. 3o, inciso VIII da Lei de Diretrizes e Base da Educação (LDB) que estabelecem a gestão democrática como o tipo de gestão adotado na educação brasileira. Esta resulta da autonomia e da participação previstas nos arts. 14 e 15 da LDB. Também foi tratada no art. 53 do ECA e é um dos objetivos fundamentais do plano nacional da educação (PNE). 
A participação política, em toda a sua inteireza e explorando todas as suas potencialidades, na gestão da coisa pública, é levada a cabo pelo homem, enquanto "animal político" e não se limita à escolha dos governantes pelos cidadãos. Os indivíduos, seres sociais, demandam a sua oitiva na tomada de decisões objetivas envolvendo diretamente seus interesses, individual e metaindividualmente considerados. E a lei é explícita em estabelecer a gestão democrática em inúmeras hipóteses, que vão desde a seguridade social à educação. Por isso é que Martins Júnior (2004:345) aponta:

Inegavelmente, a participação popular na Administração Pública é fator de legitimidade do poder político e contribuinte do princípio da transparência, implantando técnicas de conhecimento, controle e direção das atividades administrativas com caráter de repartição, partilha e solidariedade na condução política dos negócios públicos entre a Administração Pública e a sociedade, de forma a diminuir a sensível distância entre o instrumento e a destinatária da consecução do bem comum.

\section{Breve conclusão}

A administração pública societal - ou em uma visão jurídica, a democracia constitucional (ou participativa, deliberativa) - propõe uma "nova" forma de relação entre a população civil e o Estado, baseando-se em uma concepção dialógica de gerir a res publica. Trata-se de uma evolução do conceito de Estado social, que tem suas raízes ligadas ao ideário da justiça, da igualdade e da liberdade e, portanto, da democracia.

O conceito de democracia merece sempre ser revisitado. Tal releitura deve ser efetivada na praxis (jurídica e política), com a participação cada vez mais ativa dos atores responsáveis tanto pela hermenêutica e aplicação constitucional. ${ }^{10}$ Igualmente, deve ser levada a efeito pelos agentes públicos responsáveis pela realização ótima dos valores e princípios emandos da Lex Mater, com a adequada

\footnotetext{
${ }^{10}$ Em pesquisa jurisprudencial do Supremo Tribunal Federal, não se verificaram ocorrências para os verbetes "democracia participativa", "democracia deliberativa”, "deliberação democrática”, salvo as seguintes: 1. ADin nº 3.741-2, DF. Relator: Min. Ricardo Lewandowski. Requerente: Partido Social Cristão (PSC) e outros. Requeridos: Presidente da República e Congresso Nacional. Extraído do DJ de 23 fev. 2007. Ementário no 2.265-1. 2. ADPF nº 130/DF - DISTRITO FEDERAL - ARGUIÇÃO DE DESCUMPRIMENTO DE PRECEITO FUNDAMENTAL. Relator(a): Min. Carlos Britto. Julgamento: 30 abr. 2009. Órgão julgador: Tribunal Pleno. Publicação DJe-208. Divulg. 5 nov. 2009. Public. 6 nov. 2009. Ement. vol. - 02381-01 PP-00001. O tema, como se pode constatar, não tem tido repercussão jurisprudencial até o momento.
} 
implementação de políticas públicas, inclusive daquelas relativas à própria democracia representativa, direito de quarta geração (ou quarta dimensão).

Em outras palavras, se quer viabilizar a gestão democrática das políticas públicas, para citar as palavras habermasianas, ou seja, a realização da democracia participativa que transfere a soberania do Estado, para a Constituição, esta vista como o poder vivo do povo, o poder que ele não alienou em nenhuma assembleia ou órgão de representação e que, infelizmente, encontra resistências e um longo caminho a percorrer.

As fragilidades, contudo, precisam ser enfrentadas (rectius: superadas) seja viabilizando um trabalho legislativo local regulador da gestão participativa de molde a conferir eficácia plena e aplicabilidade imediata a mandamentos constitucionais (exemplo da gestão democrática da educação, que devido à inércia dos legisladores locais não goza de efetividade), seja pela implementação de novas práticas no Poder Executivo (a exemplo do orçamento participativo), seja, por fim, por meio da aplicação de uma nova hermenêutica constitucional que permita uma releitura da carta política, que atenda ao mandamento que confere o poder ao povo, como aliás está inscrito no seu art. 1ํㅡㄹ parágrafo único.

\section{Referências}

AZAMBUJA, Carmen Luiza Dias; LIMA, José Jerônimo de Menezes. Judiciário: qualidade total. Canoas: Ulbra, 1999.

BOBBIO, Norberto. Estado, governo, sociedade: para uma teoria geral da política. 6 . ed. São Paulo: Paz e Terra, 2005.

BONAVIDES, Paulo. Política e Constituição: os caminhos da democracia. Rio de Janeiro: Forense, 1985.

- Teoria constitucional da democracia participativa: por um direito constitucional de luta e resistência, por uma nova hermenêutica e por uma repolitização da legitimidade. 3. ed. São Paulo: Malheiros, 2001.

BRESSER-PEREIRA, Luiz Carlos. Auto-interesse e incompetência. Revista Brasileira de Economia (RBE), Rio de Janeiro, v. 57, n. 1, p. 209-222, jan./mar. 2003.

CAMPOS, Anna Maria. Accountability: quando poderemos traduzi-la para o português? Revista de Administração Pública (RAP), Rio de Janeiro, v. 24, n. 2, p. 30-50 fev./abr. 1990.

CHIAVENATO, Idalberto. Teoria geral da administração. 6. ed. Rio de Janeiro: Elsevier, 2002. v. I e II. 
DI PIETRO, Maria Sylvia Zanella. Parcerias na administração pública: concessão, permissão, franquia, terceirização e outras formas. 3. ed. São Paulo: Atlas, 1999.

Direito administrativo. 17. ed. Atlas: São Paulo, 2004.

Alcance do princípio da publicidade das funções públicas: transparência e sigilo. In: MORAES, Alexandre (Coord.). Os 20 anos da Constituição da República Federativa do Brasil. São Paulo: Atlas, 2009.

FAORO, Raymundo. Os donos do poder: formação do patronato político brasileiro. 3. ed. São Paulo: Globo, 2001.

FRISCHEISEN, Luíza; MOSCOGLIATO, Marcelo. Estatística de qualidade no Ministério Público Federal: um ensaio. Brasília: Escola Superior do Ministério Público da União, 2008.

GARCIA, Emerson; ALVES, Rogério Pacheco. Improbidade administrativa. 2. ed. Rio de Janeiro: Lumen Juris, 2004.

HAGE, Jorge. Um debate equivocado. Folha de S.Paulo, 29 nov. 2009. Tendências/ Debates, ano 89, no 29.460. p. A3.

HOLANDA, Sérgio Buarque de. Raízes do Brasil. São Paulo: Companhia das Letras, 2008.

MARTINS JÚNIOR, Wallace Paiva. Transparência administrativa: publicidade, motivação e participação popular. São Paulo: Saraiva, 2004.

MATIAS-PEREIRA. José. Manual de gestão pública contemporânea. São Paulo: Atlas, 2008.

MEIRELLES, Hely Lopes. Direito administrativo brasileiro. 22. ed. São Paulo: Malheiros, 1997.

MELLO, Celso Antônio Bandeira de. Curso de direito administrativo. 26. ed. São Paulo: Malheiros, 2009.

MORAES, Alexandre de. Direito constitucional. 24. ed. São Paulo: Atlas, 2009.

MOTTA, Fernando C. Prestes; VASCONCELOS, Isabella F. Gouveia de. Teoria geral da administração. 3. ed. São Paulo: Cengage Learning, 2008.

NADER, Paulo. Introdução ao estudo do direito. 31. ed. Rio de Janeiro: Forense, 2009.

PAES, José Eduardo Sabo. Fundações, associações e entidades de interesse social: aspectos jurídicos, administrativos, contábeis, trabalhistas e tributários. 6. ed. Brasília: Brasília Jurídica, 2006. 
PAULA, Ana Paula Paes de. Administração pública brasileira entre o gerencialismo e a gestão social. Revista de Administração de Empresas (RAE), v. 45, n. 1, jan./mar. 2005.

. Por uma nova gestão pública: limites e potencialidades da experiência contemporânea. Rio de Janeiro: FGV, 2005.

ROCHA, Cármen Lúcia Antunes. República e "res publica" no Brasil. In: MELLO, Celso Antônio Bandeira de (Org.). Direito administrativo e constitucional: estudos em homenagem a Geraldo Ataliba. São Paulo: Malheiros, 1997. v. 2.

SANTOS, Alvacir Correa dos. Princípio da eficiência da administração pública. São Paulo: LTR, 2003.

SIRAQUE, Vanderlei. Controle social da função administrativa do Estado: possibilidades e limites na Constituição de 1988. São Paulo: Saraiva, 2005.

TRAGTENBERG, Maurício. Burocracia e ideologia. 2. ed. São Paulo: Ática, 1992.

WEBER, Max. Economia e sociedade. Trad. Regis Barbosa e Elsabe K. Barbosa. Brasília: UnB, 2004. v. 1 e 2.

WEFFORT, Francisco C. Formação do pensamento político brasileiro: ideias e personagens. São Paulo: Ática, 2006.

ZIPPELIUS, Reinhold. Teoria geral do Estado. 3. ed. Lisboa: Fundação Calouste Gulbenkian, 1997. 